Fanum

Sociológico

\section{Forum Sociológico}

Série II

$29 \mid 2016$

Número 29

\title{
Modos de reconfiguração da ação pública num contexto de subida das incertezas : uma reflexão a partir das políticas de educação básica de adultos
}

Modes of reconfiguration of public action in a context of rising uncertainties : a reflection from the policies of basic education for adults

João Eduardo Martins

\section{OpenEdition}

Journals

\section{Edição electrónica}

URL: https://journals.openedition.org/sociologico/1524

DOI: 10.4000/sociologico.1524

ISSN: 2182-7427

Editora

CICS.NOVA - Centro Interdisciplinar de Ciências Sociais da Universidade Nova de Lisboa

\section{Refêrencia eletrónica}

João Eduardo Martins, «Modos de reconfiguração da ação pública num contexto de subida das incertezas : uma reflexão a partir das políticas de educação básica de adultos», Forum Sociológico [Online], 29 | 2016, posto online no dia 31 dezembro 2016, consultado o 31 março 2022. URL: http:// journals.openedition.org/sociologico/1524 ; DOI: https://doi.org/10.4000/sociologico.1524 


\title{
MODOS DE RECONFIGURAÇÃO DA AÇÃO PÚBLICA NUM CONTEXTO DE SUBIDA DAS INCERTEZAS: UMA REFLEXÃO A PARTIR DAS POLÍTICAS DE EDUCAÇÃO BÁSICA DE ADULTOS \\ MODES OF RECONFIGURATION OF PUBLIC ACTION IN A CONTEXT OF RISING UNCERTAINTIES: A REFLECTION FROM THE POLICIES OF BASIC EDUCATION FOR ADULTS
}

\author{
João Eduardo Martins \\ Universidade do Algarve, Faculdade de Economia, CIEO - Centro de Investigação sobre Espaço e Organizações
}

\begin{abstract}
Resumo
Faz-se neste artigo uma reflexão sobre a reconfiguração da ação pública na sociedade portuguesa a partir da análise da implementação de um programa de políticas públicas de educação de adultos com incidência nos sentidos e nos modos como os atores encarregues de o colocar em prática dele se apropriam e o reinterpretam. Os resultados da investigação aqui mobilizada permitem dizer que a produção da ação pública é atravessada por lógicas de ação múltiplas e não poucas vezes de sentido contrário entre si, o que é revelador das tensões, ambivalências e contradições pelas quais são atravessadas as políticas e as práticas de educação de adultos num contexto contemporâneo de subida de múltiplas incertezas. A produção da ação pública é hoje o resultado da intervenção de uma multiplicidade de atores com características marcadamente diferenciadas numa ação construída coletivamente a múltiplos níveis.
\end{abstract}

Palavras-chave: Sociologia, ação pública, educação de adultos, subida das incertezas

\begin{abstract}
In this article we propose a reflection about the reconfiguration of public action in the Portuguese society, through the analysis of the implementation of a public policy program for adults' education, with incidence in the meanings and the modes of how the actors in charge of putting it into practice appropriate and reinterpret it. The research results allow us to say that the production of public action is crossed by multiple logics of action, quite often opposite, thus revealing the tensions, ambivalences and contradictions that permeate adults' education policies and practices in a contemporary context of rising uncertainties. The production of public action is, nowadays, the result of the intervention of a multiplicity of actors with markedly different characteristics within an action collectively built at multiple levels.
\end{abstract}

Keywords: Sociology, public action, adult education, rising uncertainties

\section{Introdução}

Este artigo tem como principal objetivo a reflexão sobre os modos de implementação das políticas públicas de educação básica de adultos em Portugal a partir da análise do programa "Iniciativa Novas Oportunidades". Mobilizam-se os resultados empíricos de uma investigação de doutoramento em Sociologia realizada na Faculdade de Ciências Sociais e Humanas da Universidade Nova de Lisboa intitulada "Das políticas às práticas de educação de adultos: Lógicas de ação, sentidos e modos de apropriação localmente produzidos" com a finalidade de compreender sociologicamente os modos como a medida se enraíza localmente nos terrenos da ação pública. 
Privilegia-se a reflexão sociológica em torno de dois eixos analíticos centrais desenvolvidos ao longo do trabalho. O sistema de sentidos em torno das finalidades da medida e as lógicas de ação que orientam a intervenção dos formadores de educação e formação de adultos e dos técnicos de reconhecimento, validação e certificação de competências entrevistados no âmbito desta investigação.

Do ponto de vista metodológico, a investigação posiciona-se do lado das sociologias interpretativas, seguindo uma lógica qualitativa, e procurou conciliar um esquema de inteligibilidade actancial com um esquema estrutural (Berthelot, 1997). Foram realizadas trinta e oito entrevistas semiestruturadas a técnicos que trabalharam na Iniciativa Novas Oportunidades em duas organizações situadas na região do Algarve: uma Associação de Desenvolvimento Local e um Centro de Formação Profissional, este último sob tutela estatal.

As entrevistas foram feitas a técnicos de Reconhecimento, Validação e Certificação de Competências, técnicos de Diagnóstico e Acolhimento, mediadores e formadores de cursos de Educação e Formação de Adultos (EFA) e um diretor de um Centro Novas Oportunidades. Para além de 8 entrevistas exploratórias feitas a formadores que trabalham em entidades públicas e privadas, foram realizadas 17 entrevistas na Associação de Desenvolvimento Local e 13 entrevistas no Centro de Formação Profissional. Os formadores entrevistados dão formação nas áreas de competência-chave Linguagem e Comunicação, Cidadania e Empregabilidade, Matemática para a Vida, Tecnologias da Informação e da Comunicação, Inglês, assim como nas áreas da formação profissionalizante.

Foram entrevistados formadores em áreas tão diversificadas tais como Animação e Lazer, Tratamento de Plantas e Animais, Higienização de Espaços e Equipamentos ou Lavandaria e Tratamento de Roupas, em cursos EFA - B3 e B4, cursos que dão equivalência a um grau de escolaridade ao nível do $9^{\circ}$ ano e do $12^{\circ}$ ano respetivamente e a níveis II e III de certificação profissional. Estes técnicos que trabalham na formação de adultos são provenientes, nas suas trajetórias académicas, de áreas tão diversificadas, tais como a Gestão de Empresas, a Matemática, a Sociologia, a Antropologia, a Engenharia Alimentar, a Enfermagem, a Engenharia de Sistemas de Informação, entre outras, sendo esta diversidade uma caraterística marcante da trajetória destes atores, cuja experiência e trajetória profissional está também marcada pela pluralidade de mundos ocupacionais.

Do ponto de vista da sua estrutura etária, estamos perante uma categoria ocupacional relativamente jovem, com uma média de idades de aproximadamente 37 anos, e situada socialmente, do ponto de vista da sua trajetória social, na nova pequena burguesia com um elevado capital escolar, sendo na sua maioria licenciados. Uma caraterística que contrasta com a escolaridade dos seus pais, que para além de ocuparem posições no espaço social manifestamente inferiores do ponto de vista estatutário, têm níveis de escolaridade comparativamente muito baixos (Martins, 2014: 154). O material empírico recolhido foi sujeito a uma análise estrutural de conteúdos (Hiernaux, 1997) com o objetivo de identificar os modelos culturais ${ }^{1}$ que orientam a conduta dos atores.

Do ponto de vista da orientação teórica, as principais referências analíticas são a sociologia política da ação pública (Hassenteufel, 2008) com centralidade do conceito de ação pública²; a sociologia da individuação (Martuccelli, 2006) com centralidade no conceito de prova ${ }^{3}$ (épreuve) e os conceitos de procedimentalização (De Munck e Verhoeven, 1997) e de agir poiético, operadores analíticos estes adequados à análise da ação pública levada a cabo num contexto de subida das incertezas (Castel, 2009).

Os resultados desta investigação permitem-nos pensar os processos e as dinâmicas de reconfiguração da ação pública na sociedade portuguesa e constatar que esta é hoje atravessada por tensões, ambivalências e contradições que os atores encarregues da sua produção têm que enfrentar a quando da sua intervenção coletiva conjunta. A medida é atravessada por atribuições de sentido contraditórias e por lógicas de ação diversas que geram tensões no momento da sua apropriação.

Existe assim uma tensão entre uma lógica de massificação e uma lógica de singularização; entre uma lógica universalista e uma lógica de seleção social e entre uma lógica de implementação (Pressman e Wildawsky, 1973) emanada do topo do Estado e uma de lógica da ação coletiva valorizada pelos atores no local. Em seguida apresentamos esta combinatória de sentidos e de lógicas de ação tal como eles se manifestam no material empírico recolhido na investigação.

\section{Uma medida que repara injustiças, mas que também produz injustiças}

Os sentidos atribuídos pelos técnicos entrevistados às finalidades da medida Novas Oportunidades, permitem-nos dizer que se por um lado esta medida de política pública é percecionada como reparadora de injustiça social, uma vez que permite uma nova oportunidade educativa a indivíduos que foram anteriormente afastados do sistema educativo, em resultado de causas exteriores à responsabilidade individual dos mesmos; por outro lado, a medida é percecionada como produtora de injustiças, quando é encarada como oferecendo novas oportunidades de vida a indivíduos que aparecem nas representa- 
ções dos formadores como não fazendo nada para as merecer.

Emergem assim do material empírico dois sistemas de representações que remetem para a oposição entre beneficiários merecedores e não merecedores. Os primeiros são percecionados como aqueles que verdadeiramente merecem as oportunidades que o sistema põe à sua disposição. Os segundos são percecionados como não fazendo nada para merecer as oportunidades que lhes estão a ser proporcionadas.

Nas representações dos entrevistados é muito clara esta dicotomia, de um lado, os "bons" beneficiários da Iniciativa, aqueles para quem de fato as Novas Oportunidades valem a pena; do outro lado, os "maus" beneficiários que frequentam a medida, aqueles que se aproveitam do sistema ou que são percebidos como não sendo talhados para a frequência do mesmo. Este segundo conjunto de representações sociais dos técnicos sobre os destinatários desta medida de política educativa permite-nos pensar que estamos na presença de um dos mais poderosos mecanismos de legitimação das desigualdades sociais tal como identificados por Martuccelli (2006) e que passa pela responsabilização dos indivíduos pelo seu (in)sucesso na frequência do programa.

Mesmo quando os beneficiários deste tipo de iniciativa são vistos como tendo sido objeto de mecanismos injustos de reprodução cultural e social, aquando da sua passagem pela instituição escolar, é à responsabilização dos beneficiários pelo seu próprio desempenho, o mecanismo a que uma boa parte dos educadores de adultos entrevistados recorre para posicionar o público-alvo com que trabalha. A capacidade de ativação de si próprio no trabalho com o outro (Astier, 2003) e sobre o outro (Dubet, 2002) é o mecanismo que legitima o sucesso do trabalho dos adultos que frequentam as ações de formação dos cursos de educação e formação de adultos.

Deste modo, esta medida de política pública, através da mediação da intervenção dos técnicos, tanto pode funcionar como um dispositivo de seleção social, afastando aqueles que são considerados como não aptos ou sem vontade própria de irem ao encontro do novo paradigma de políticas públicas centrado nas exigências da ativação 4 (Cassiers, 2005) como pelo contrário pode funcionar como um dispositivo capaz de produzir uma nova confiança institucional em si (Martuccelli, 2006) quando os indivíduos se movem na direção desejada pela normatividade da medida e da exigência dos técnicos.

Vejamos a título de ilustração o discurso do formador Américo, antropólogo, formador de Cidadania e Empregabilidade, num curso EFA - B3 (com equivalência escolar ao $9.0^{\circ}$ ano de escolaridade) para quem o sucesso do seu trabalho depende da vontade individual dos destinatários em quererem efetivamente mudar de vida:

"A principal dificuldade é uma que deriva daquela questão que the falei há bocado, é de estarmos a trabalhar com pessoas que efetivamente não querem mudar, isto é, os cursos EFA para mim são cursos de mudança, são cursos em que existem condições para a pessoa mudar, mudar erros de comportamento e de atitudes que teve, erros de posicionamento face à sociedade (...) portanto, há aqui uma série de situações e oportunidades que os cursos EFA permitem pegar e trabalhar e ajudar as pessoas que querem, a mudar, mudar de forma de vida, mudar de profissão, mudar claramente a qualidade da sua vida, agora, essa é uma realidade para a maior parte dos formandos que nos chegam à seleção ou que nos chegam à sala de formação, mas não é para todos. Isto é, alguns formandos ainda são profissionais da formação, estão aqui com um único objetivo que é ganhar umas massas durante algum tempo (...) as pessoas que embarcarem neste caminho de dependência vêm aqui com um esquema de realização de algumas mais-valias, essas não querem mudar, essas pessoas não fazem esta transformação individual, pessoal, para beneficiarem de todos estes recursos que estão aqui há disposição delas para evoluir e com essas, realmente, trabalha-se mal, é difícil e os processos, as aprendizagens, são complicadas, são difíceis, rejeitam, perturbam, é difícil. As que querem mudar, é pá, trabalha-se muito bem com elas (...) o problema está no identificar genuinamente aquelas que querem embarcar num processo de mudança e as que não querem embarcar num processo de mudança. Repare, há aquelas para as quais isto é só um esquema, uma forma de prolongar a sua existência mais ou menos miserável durante mais alguns tempos."

\section{Trabalhar sobre o singular e certificar o maior número: entre a singularização e a massificação}

Uma das isotopias (Hiernaux, 1997) construídas a partir do material empírico analisado nesta investigação permitiu-nos objetivar uma tensão, entre uma lógica de ação centrada na massificação do dispositivo e uma lógica de ação centrada na singularização. A primeira resulta de uma racionalidade emanada do topo do campo burocrático centrada na produção quantitativa de metas e na exigência da eficácia e eficiência dos resultados. A segunda emanada dos "profissionais" que nos 
Quadro $1 \triangleright$ Lógicas de ação em confronto na implementação da Iniciativa Novas Oportunidades/Tensões e contradições entre a massificação e a singularização

\begin{tabular}{|c|c|c|}
\hline $\begin{array}{c}\text { As metas são muito difíceis de alcançar } \\
\text { Ninguém atinge as metas } \\
\text { É uma correria constante para atingir as metas } \\
\text { Nalgumas entidades a Iniciativa Novas } \\
\text { Oportunidades pode promover o facilitismo } \\
\text { Seria preciso deixar fazer um trabalho com mais } \\
\text { qualidade } \\
\text { As metas deviam ser reavaliadas para podermos } \\
\text { fazer um trabalho de qualidade } \\
\text { Lógica quantitativa/massificação }\end{array}$ & / & $\begin{array}{c}\text { [As metas não são muito difíceis de alcançar] } \\
\text { [Alguém atinge as metas] } \\
\text { [Não é uma correria constante para atingir as metas] } \\
\text { [Nalgumas entidades a Iniciativa Novas } \\
\text { Oportunidades não pode promover o facilitismo] } \\
\text { [Não seria preciso deixar fazer um trabalho com } \\
\text { mais qualidade] } \\
\text { [As metas não deviam ser reavaliadas para } \\
\text { podermos fazer um trabalho de qualidade] } \\
\text { Lógica qualitativa/singularização }\end{array}$ \\
\hline
\end{tabular}

terrenos da ação pública se confrontam com as provações do trabalho de formar e de reconhecer e validar competências, mais centradas na qualidade do seu trabalho. Este último assenta na necessidade de fabricar respostas singularizadas ${ }^{5}$ ao percurso individual e formativo de cada adulto destinatário destes dispositivos de formação.

A descrição da isotopia diz-nos assim que "as metas são muito difíceis de alcançar", que "nunca ninguém atinge as metas", que as "metas são muito apertadas", que para se atingir as metas estabelecidas estatalmente tem que se andar "numa correria constante" e que as metas deveriam ser reavaliadas para se poder fazer "um trabalho de qualidade".

Estamos perante uma lógica de ação Estatal que privilegia a dimensão de Estado Avaliador (Neave, 1988) com ênfase na eficácia dos resultados, no apelo à certificação do maior número e na exigência na produção de certificados. É preciso chegar a um certo número de metas traçadas num determinado período de tempo, funcionando desta forma à maneira da cité industrielle (Boltanski e Thévenot, 1991).

Do lado dos atores que trabalham no terreno, a pressão para o cumprimento de metas é sentida de forma ambivalente, uma vez que, se por um lado, são constrangidos pela ação estatal a orientarem-se para o cumprimento dos objetivos estipulados, sob pena de verem o seu próprio posto de trabaIho em risco; por outro lado, os testemunhos dos entrevistados assinalam uma preocupação com a difícil conciliação entre a resposta à exigência da massificação e uma ética profissional orientada pela valorização de se fazer um trabalho de qualidade que tenha em atenção a especificidade de cada indivíduo no singular.

\section{Entre uma lógica de ação universal e uma lógica de ação orientada pela seletividade: um programa só para alguns}

Esta é outra tensão importante que encontramos na análise ao material empírico e com que se defrontam os atores no terreno no momento da apropriação da medida. Por um lado, uma lógica de ação emanada estatalmente, assente no princípio da universalidade, e por outro lado, uma lógica de ação defendida pelos técnicos entrevistados, orientada pela exigência de seletividade da medida. Reconhecer, validar e certificar competências não deveria ser um dispositivo de educação de adultos aberto a todos, mas pelo contrário, deveria ser só para alguns.

O discurso de Narciso, o Diretor de um Centro Novas Oportunidades numa Associação de Desenvolvimento Local é ilustrativo a este respeito:

\footnotetext{
"(...) essa política dos Centros Novas Oportunidades foi pensada para pessoas para mais de 23 anos, em que a perspetiva era ter um leque de várias ofertas e no caso específico dos Centros de RVCC, para pessoas que tinham uma trajetória pessoal de vida bastante rica e de claramente de produção de competências que permitiria que essas pessoas se dirigissem aos Centros e viessem reconhecer essas competências. O que acontece depois é que esta política, na sua génese bastante rigorosa e até generosa, se transformou num instrumento político muito mais universal e muito mais de banda larga; e quando eu digo universal significa, não é no bom sentido, é: universalizou-se uma medida que não era para ser universal, ou seja, abriu-se a partir dos 18 anos e não necessariamente para pessoas que
} 
já tinham uma trajetória de vida e então os Centros foram um pouco forçados a receber aqui pessoas que não tinham propriamente perfil para fazer isto (...) e nós acabámos por ter que acolher aqui pessoas que não tinham na altura o devido perfil e claramente os processos acabaram por se arrastar muito com essas pessoas porque naturalmente tinha que ser assim (...) os Centros Novas Oportunidades, primeiramente Centros RVCC não poderiam ter sido encarados como uma política universal para todas as pessoas que não tinham escolaridade obrigatória mas sim uma política seletiva para pessoas que exatamente tinham esse perfil."

Os destinatários considerados "sem perfil" são uma prova (Martuccelli, 2006) difícil de ultrapassar no trabalho quotidiano dos técnicos que muitas vezes não encontram soluções alternativas para a sua situação e só lhes resta convencer esta categoria de adultos das suas "incompetências".

"(...) há aqui também outro problema de gestão com o qual fomos confrontados em que não há ou não houve durante este período esse leque alargado de ofertas, quem não tinha perfil para este processo não havia propriamente grandes alternativas para reencaminhar, durante muito tempo não tivemos cursos EFA no Algarve e agora continuamos sem ter, ou seja, uma pessoa que não tem competências para fazer o processo de RVCC, para onde é que a reencaminhamos? A não ser que digamos à pessoa, você não pode fazer isto, não tem perfil, fica em lista de espera até que haja uma oferta e essas ofertas não existiram. Então, do ponto de vista da conceção política, ela depois acabou por ter muito mais consistência, penso eu, mas falhou porque não existiram os instrumentos de suporte."

"(...) por exemplo, claramente, há pessoas para quem esta política se adequa na perfeição.
Pessoas que tiveram vidas riquíssimas e que só precisavam de um instrumento deste tipo para demonstrar o que aprenderam ao longo da vida e essas pessoas não são claramente a maioria. São uma minoria de pessoas que certamente passaram por todos os Centros em Portugal, mas justifica a necessidade da medida, depois há muita gente que por aqui tem passado para quem, digamos, o Centro tal como ele foi concebido não era claramente a resposta e que nos obrigou a ter respostas alternativas de trabalho suplementar com essas pessoas para produção de competências e não apenas para reconhecimento. $\mathrm{E}$, portanto, eu diria que há um leque interessante de pessoas a quem o reconhecimento é uma resposta clara e justa e depois há uma série de outras pessoas para que o reconhecimento é meramente insuficiente e o trabalho de produção de competências, aí, nesse caso de formação, é muito mais forte, muito mais pesado e veja-se o caso dos desempregados não é? O Centro Novas Oportunidades, nós somos neste momento desde há uns meses atrás, somos obrigados, somos obrigados, mas os desempregados também são obrigados (...) o desempregado é obrigado sobre a chantagem de perder o subsídio de desemprego a fazer o reconhecimento de competências (...) ou vão fazer o processo de RVCC ou perdem o subsídio de desemprego, portanto há muitas incoerências nesta matéria e claramente são medidas políticas mal feitas, inconcebíveis, quer dizer, não é por essa via, quer dizer e há muita gente que ali está que não tem perfil e o que nós fazemos é levar as pessoas a perceber que não têm perfil, o senhor não tem perfil, o senhor não pode fazer isto, isto não vai resolver o seu problema."

A tensão sentida pelos entrevistados que têm a seu cargo a tarefa de executar as políticas é clara: a medida não deveria ser aberta a todos a que ela chegam. É isso que nos permite perceber o sistema de sentidos que emerge do quadro que se segue.

Quadro $2 \triangleright$ Os constrangimentos na implementação da Iniciativa Novas Oportunidades/Entre o universalismo e a seletividade

\begin{tabular}{|c|c:c|}
\hline $\begin{array}{c}\text { [Política não universal e de banda curta] } \\
\text { Universalidade vista como negativa }\end{array}$ & $/$ & Política universal e de banda larga \\
[ & $/$ & I \\
[Universalidade vista como positiva]
\end{tabular}


A ambição política da medida deveria ser reduzida uma vez que ela é encarada como devendo ser aberta só para alguns sem pretensões da sua universalidade. Nem todos os beneficiários têm uma trajetória de vida que permita um reconhecimento de competências aos níveis exigidos. Em muitas situações há défices nas ofertas alternativas da política de educação e formação de adultos, o que deixa os técnicos no terreno de mãos atadas sem saber para onde reencaminhar os adultos que são percebidos como "sem perfil". Em muitas outras situações, chegam à medida pessoas que a ela acedem de forma forçada, uma vez que, sob a égide ideológica das políticas de ativação, os desempregados são obrigados a frequentar a formação contrariados, sob pena de verem cortados os subsídios alocados pelo Estado. Uma provação difícil de resolver nos terrenos da ação pública.

\section{Estado Poiético, lógica de implementação e lógica da ação coletiva: tensões, contradições e ambivalências na produção da ação pública}

As políticas públicas de educação básica de adultos, à semelhança das políticas públicas noutros setores de atividade, passam um processo de reconfiguração societal que as tornam analisadores por excelência das transformações do papel do Estado nas sociedades ocidentais contemporâneas.

Constrangida a partir do exterior na sua intervenção por atores transnacionais que lhe diminuem cada vez mais a soberania e a capacidade autónoma de produção das políticas e constrangida a partir dos territórios locais por movimentos e associações da sociedade dita civil que procuram fazer prevalecer as suas expetativas, a atuação do Estado, na produção da ação, é obrigada a reinventar-se na direção daquilo que Balsa (2012) designa por Estado Poiético.

O Estado passa a produzir orientações de políticas latas e abre espaço a uma enorme diversidade de atores, públicos e privados, para levar a cabo as suas intenções e finalidades de política pública. A Iniciativa Novas Oportunidades é um claro exemplo disso, uma vez que para além das entidades públicas, sob tutela estatal, tais como as escolas e os centros de formação profissional do Instituto de Emprego e Formação Profissional, atores múltiplos de características heterogéneas e diversas, intervêm na concretização da medida. Sindicatos, organizações económicas, autarquias, empresas privadas de formação profissional, associações de desenvolvimento local, entre outras.

Um dos contributos da análise sociológica que fazemos a esta medida é percebermos que se o Estado faz apelo a uma diversidade de atores para levar à prática a ação pública, ele não deixa de chamar a si uma lógica de implementação, que à maneira Top Down, transforma a reinterpretação da medida nos locais onde ela é implementada, num processo atravessado por enormes contradições e ambivalências.

Disso nos dá conta um dos formadores entrevistados no terreno, quando denuncia a ausência de participação dos atores nos processos de construção e de implementação da mesma.

\footnotetext{
"As entidades do terreno não podem, não devem ser consideradas meras extensões do Estado, daquilo que o Estado não faz, portanto, somos extensões, somos executores de políticas para as quais nós não fomos consultados, para a definição das quais nós não fomos consultados."

"Nós somos o recheio de uma sandes cuja parte debaixo do pão é este público que temos que é problemático e a parte de cima é a máquina administrativa que nos esmaga."
}

Vale a pena mobilizar aqui o pensamento de Crozier (1994) quando na sua obra "A empresa à escuta" realça a importância da escuta ativa nos processos de aprendizagem coletiva. Segundo este autor, esta é mesmo uma condição fundamental da condução dos processos de mudança e de transformação social de um qualquer sistema de ação concreto.

A escuta ativa dos atores é sentida pelos responsáveis das entidades no terreno como uma ausência, o que condiciona negativamente a implementação do programa, gerando efeitos perversos negativos, naquilo que é o seu entendimento da "boa execução" da medida. Podemos dizer, em certo sentido, que estamos perante uma crise da inteligência (Crozier, 1995) da ação do Estado, que desperdiça o saber local resultante das aprendizagens dos atores com as questões colocadas pelas provações do seu trabalho quotidiano nos terrenos da ação pública.

O sistema de sentidos que nos remete para uma lógica de implementação permite-nos dizer que "eles", a Agência Nacional para a Qualificação (ANQ), fazem as avaliações e fica-se com a sensação ("nós") que as avaliações não servem para nada e que as pessoas no terreno não são ouvidas. Não se consulta quem conhece as dificuldades do terreno. Quem desenha a medida está fechado nos gabinetes e não conhece a realidade em que vivem as pessoas que são destinatárias deste programa de ação governamental. A administração não fala com os cidadãos. Há ausência de diálogo e daí resultam imensas confusões e desajustamentos no terreno. O Estado atua numa lógica Top Down, introduzindo a determinado momento, uma lógica autopoiética, com o objetivo de chamar a si o controlo da medida. 
Quadro $3 \triangleright$ Entre a lógica de implementação e a lógica da construção coletiva da ação pública - um Estado que não escuta ativamente os parceiros da ação pública

\begin{tabular}{|c|c|c|}
\hline $\begin{array}{l}\text { Eles (ANQ) fazem avaliações a sensação que nos dá } \\
\text { é que aquilo não serve para nada } \\
\text { Não ouvem as pessoas no terreno } \\
\text { Não consultam quem conhece as dificuldades do } \\
\text { terreno } \\
\text { Não conhecem a realidade em que vivem estas } \\
\text { pessoas } \\
\text { A administração não fala com os cidadãos neste } \\
\text { país } \\
\text { Não há diálogo e daí resultam imensas confusões } \\
\text { no terreno } \\
\text { Aparece tudo desajustado daquilo que acontece no } \\
\text { terreno } \\
\text { Uma lógica de implementação - Top Down - } \\
\text { Autopoiésis }\end{array}$ & I & 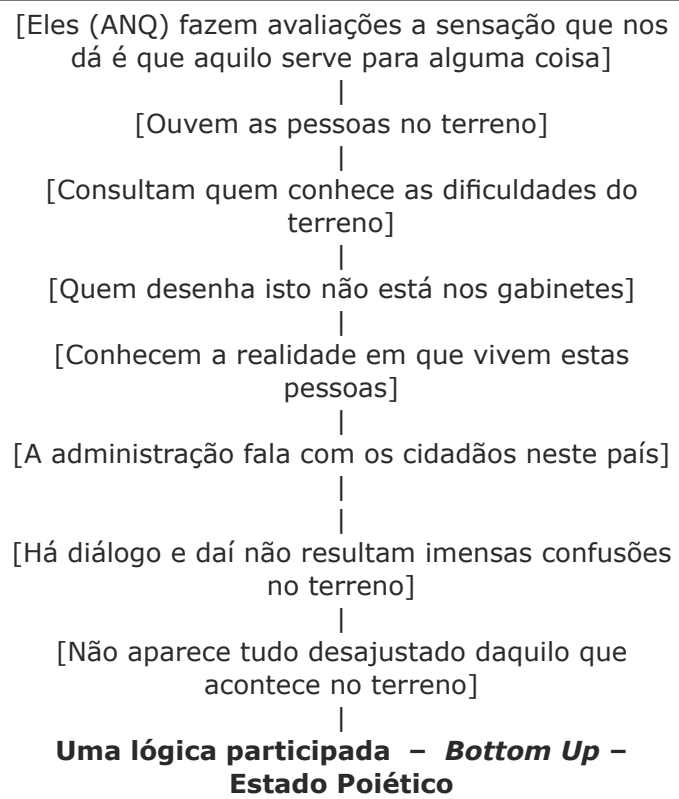 \\
\hline
\end{tabular}

O sistema de sentidos opostos abre espaço para pensar uma lógica da participação coletiva que é de fato valorizada pelos entrevistados. O Estado avalia a medida e a sensação que se fica é que as avaliações servem para alguma coisa no sentido de se transformarem as situações. Ouvem-se as pessoas no terreno. Consulta-se que conhece as dificuldades do trabalho decorrente da sua prática diária. Quem desenha a medida não se limita a estar fechado nos gabinetes. Conhece-se a realidade em que vivem os destinatários. A administração comunica efetivamente com os cidadãos. Há diálogo e esse diálogo evita as confusões e os desajustamentos na implementação da medida. A lógica valorizada baseia-se numa participação alargada de todos os atores a partir de baixo. O modelo Bottom-Up é uma condição necessária à atuação do Estado no modo poiético.

\section{Reflexões finais}

Para concluir vale a pena destacar que a análise da implementação da Iniciativa Novas Oportunidades permite-nos pensar sociologicamente as transformações na atuação do Estado na produção da ação pública. Se no contexto da sociedade portuguesa atual, à semelhança da maior parte das sociedades contemporâneas do mundo dito Ocidental, o aparelho estatal já não tem capacidade e recursos para implementar por si só as políticas públicas que quer levar a cabo, e neste caso em particular as políticas públicas de educação e formação de adultos, e portanto, para fazer face aos problemas públicos com que se confronta, o Estado mobiliza os mais diversos atores da sociedade civil para, numa lógica de parceria como os mesmos, coproduzir a ação pública. O Estado não deixa nunca, como refere Balsa (2012) de intervir no sentido de assumir o controlo da situação numa lógica autopoiética.

Neste sentido, é o Estado que continua a definir o essencial das políticas, muitas das vezes sem escutar os atores no terreno, e a decidir unilateralmente sobre os modos de produção das políticas. Esta intervenção obedece também, não poucas vezes, a uma mera lógica instrumental em que o fazer por fazer, assente numa hegemonia da racionalidade económica e financeira, se sobrepõe às finalidades éticas do próprio Estado, e, portanto, se sobrepõe às finalidades do próprio fazer.

Este é, aliás, um dos grandes paradoxos que atravessa o programa de políticas públicas aqui em análise que foi sendo objeto de um desinvestimento financeiro progressivo pelo governo da direita, na altura no poder. Foi sendo objeto de uma crescente incomunicabilidade entre o poder do Estado e os responsáveis pelas entidades no terreno. Foi atravessado por uma crescente politização e luta ideológica na arena pública pelos diferentes partidos políticos. E acabaria por ser desmantelado por iniciativa governamental ficando para a História da Educação as palavras do Primeiro-Ministro Pedro Passos Coelho de que a Iniciativa Novas Oportunidades mais não faria do que produzir uma "certificação da ignorância" (Martins, 2014). 
O trabalho dos formadores de adultos no âmbito das Novas Oportunidades é também marcado pela prova central do agir social num contexto de múltiplas incertezas. A incerteza do resultado do trabalho com o outro e sobre o outro com qual se faz a sua intervenção no sentido da passagem muitas vezes de indivíduos por defeito (Castel, 2009: 434) a indivíduos com cidadania plena reintegrados socialmente.

A incerteza resultante de uma identidade profissional não poucas vezes incerta, múltipla, fragmentada e ambígua resultante da inserção de O Novo Espírito do Capitalismo (Boltanski e Chiapello, 1999) e da competição inerente à integração na cidade por projeto. A incerteza resultante da precariedade da condição laboral inerente à vulnerabilidade do ofício de formador (Martins, 2014: 179). A incerteza resultante da descontinuidade das políticas públicas de educação e formação de adultos sempre sujeitas aos ciclos governativos, às conceções ideológicas dos diferentes governos e aos financiamentos Estatais e Europeus fortemente voláteis.

Num contexto de financeirização global da economia, a ação pública está cada vez mais liberta de uma conceção centrada no Estado na produção das políticas que o Estado pretende implementar. Está simultaneamente cada vez mais dependente dos múltiplos atores de características marcadamente diferenciadas e heterogéneas que a produzem a múltiplos níveis da sua conceção e implementação e é atravessada por inúmeras tensões e contradições.

É neste contexto que, do ponto de vista científico, ganha relevo uma Sociologia que se preocupa com a análise da ação pública nos terrenos onde ela é apropriada para se dar conta dos processos da sua reconfiguração. Por outro lado, no caso da análise da implementação da Iniciativa Novas Oportunidades, uma compreensão mais holística desta medida passaria pela construção de um olhar a partir das perspetivas daqueles que a conceberam e pilotaram, assim como daqueles a quem ela se destinou. Pensamos que a pluralidade de entradas e de pontos de vista nos diferentes níveis onde as políticas são interpretadas e reinterpretadas são um elemento fundamental de uma adequada compreensão sociológica.

\section{Notas}

1 Seguimos aqui a proposta de Jean-Pierre Hiernaux que nos diz que os modelos culturais são "sistemas de sentido típicos que orientam o comportamento dos sujeitos, que são interiorizados, socialmente produzidos, reproduzidos ou transformados" (Hiernaux, 1997: 161). A análise estrutural de conteúdos procura, a partir dos conteúdos manifestos no corpus do material empírico, encontrar as representações sociais, os sentidos que organizam e orientam a conduta dos atores. Assim sendo, o que interessa na análise, é o que está para lá do que é manifestado no texto e que vai permitir a compreensão do agir dos indivíduos em sociedade.
2 O conceito de ação pública assinala uma mudança paradigmática na leitura sociológica da análise das políticas públicas uma vez que rompe com uma visão centrada no Estado da produção e da implementação das políticas e ao mesmo tempo rompe com uma análise das políticas a partir de cima numa conceção implementacionista e sequencial que no parece redutora da compreensão dos modos como as políticas públicas se reconfiguram na contemporaneidade. Como assinala Hassenteufel (2008: 101) a abordagem da ação pública a partir de baixo reveste-se de um triplo interesse, em primeiro lugar ela abre a via para uma nova perspetiva de análise das políticas públicas partindo das interações dos atores em torno de lógicas múltiplas. Em segundo lugar, esta abordagem revela-se particularmente pertinente a um tipo específico de políticas públicas, as políticas procedimentais, cujo objetivo central é organizar e estruturar as interações dos intervenientes na produção das políticas, o que deixa uma margem de manobra significativa aos atores que estão encarregues da implementação das medidas nos terrenos da ação pública. Em terceiro lugar, esta abordagem permite apreender as interdependências multiníveis a partir da construção coletiva da ação pública. Os níveis local, nacional e transnacional podem assim ser apreendidos a partir da análise de situações concretas sócio-historicamente localizadas (Martins, 2014: 72).

3 O conceito de prova é central na sociologia da individuação de Danilo Martuccelli (2006) e é o operador concetual a que recorremos nesta investigação para compreender os modos de apropriação da medida de política educativa aqui em análise. Martuccelli (2006) define as provas como os desafios históricos, socialmente produzidos, desigualmente distribuídos, que os indivíduos são confrontados a enfrentar. Trata-se de perceber como os indivíduos enfrentam as provações com que se deparam nas suas existências quotidianas numa determinada singularidade sociohistórica.

4 As políticas de ativação remetem para um novo modo de regulação societal da atuação do Estado centrada na ideia de Estado Social Ativo cuja ideia central é a de ativar os indivíduos que são objeto de intervenção do Estado, transformá-los em autores das suas vidas, responsabilizá-los pela sua própria trajetória e destino social. Estas políticas demarcam-se claramente da ideia de um Estado Social Passivo, visão tradicional da atuação do Estado-Providência, centrado no assegurar de direitos sociais e da atribuição das alocações atribuídas pelo Estado sem as contrapartidas inerentes em termos de deveres sociais exigidos aos beneficiários. Trata-se de um novo contrato social muito mais exigente na produção social dos indivíduos (Martins, 2014: 234; Vrancken e Macquet, 2006: 83).

5 Sobre os processos em curso de singularização societal recomendamos vivamente a obra de Martuccelli (2010) sobre a sociedade singularizada, e cuja leitura nos ajuda a compreender melhor esta tensão entre as lógicas de massificação e as lógicas de singularização.

\section{Referências bibliográficas}

ASTIER, I. (2003), "L'irruption de I'individu concret dans le service public: du travail sur autrui au travail avec autrui", comunicação apresentada na IX Journées de Sociologie du Travail, 27-28 de novembre 2003, Paris, França. 
BALSA, C. (2012), "Estado Poiético, autopoiesis e agir poiético - A coordenação em rede das políticas de desenvolvimento social em Portugal como instrumento de luta contra a pobreza", in Adilson Marques Gennari e Cristina Maria Pinto Albuquerque (orgs.), Políticas públicas e desigualdades sociais - Debates e práticas no Brasil e em Portugal, Série Relações Internacionais e Mundo Contemporâneo, São Paulo, Ed. Cultura Académica.

BERTHELOT, J.M. (1997), A inteligência do social, Porto, Res Editora.

BOLTANSKI, L. e È. Chiapello (1999), Le nouvel esprit du capitalisme, Paris, Éditions Gallimard.

BOLTANSKI, L. e L. Thévenot (1991), De la justification. Les économies de la grandeur, Paris, Gallimard.

CASSIERS, I. (2005), "De l'État providence à l'État social actif: quelles mutations sous-jacentes?", Regards Économics, Institut de Recherches Economiques et Sociales de I'Université Catholique de Louvain.

CASTEL, R. (2009), La montée des incertitudes. Travail, protections, statut de l'individu, Paris, Éditions du Seuil.

CROZIER, M. (1994), A empresa à escuta, Lisboa, Instituto Piaget.

CROZIER, M. (1995), La crise de l'intelligence. Essai sur l'impuissance des élites à se reformer, Paris, InterEditions.

DE MUNK, J. e M. Verhoeven (1997), Les mutations du rapport à la norme. Un change- ment dans la modernité?, Bruxelles, De Boeck Université.

DUBET, F. (2002), Le déclin de l'institution, Paris, Éditions du Seuil.

HASSENTEUFEL, P. (2008), Sociologie Politique: I'action publique, Paris, Armand Colin.

HIERNAUX, J. P. (1997), "Análise estrutural de conteúdos e modelos culturais: aplicação a materiais volumosos", in L. Albarello et al. (eds.), Práticas e métodos de investigação em Ciências Sociais, Lisboa, Gradiva.

MARTINS, J. (2014), Das políticas às práticas de educação de adultos. Lógicas de ação, sentidos e modos de apropriação localmente produzidos, Lisboa, Colibri.

MARTUCCELLI, D. (2006), Forgé par l'épreuve. L'individu dans la France contemporaine, Paris, Armand Colin.

MARTUCCELLI, D. (2010), La société singulariste, Paris, Éditions Armand Colin.

NEAVE, G. (1988), "On the Cultivation of Quality, Efficiency and Enterprise: An Overview of Recent Trends in Higher Education in Western Europe, 1968-1988", European Journal of Education, 23 (1/2), pp. 7-23.

PRESSMAN, J e A. Wildawsky (1973), Implementation, Los Angeles, University of California Press.

VRANCKEN, D. e C. Macquet (2006), Le travail sur soi. Vers une psychologisation de la société?, Paris, Éditions Belin.

Recebido a 31/05/2016. Aceite para publicação a 18/11/2016.

João Eduardo Martins (jrmartins@ualg.pt). Universidade do Algarve, Faculdade de Economia, CIEO - Centro de Investigação sobre Espaço e Organizações, Edifício 9, Campus de Gambelas, 8005-139 Faro, Portugal. 